\title{
Efficacy and Safety of DWJ1252 Compared With Gasmotin Treatment: Once Met 3 Times Tablets
}

\author{
Jae Hak Kim \\ Department of Internal Medicine, Dongguk University College of Medicine, Dongguk University Ilsan Hospital, Goyang, Gyeonggi-do, Korea
}

Article: Efficacy and safety of DWJ1252 compared with gasmotin in the treatment of functional dyspepsia: a multicenter, randomized, double-blind, active-controlled study

Park JH, Lee KN, Lee OY, et al

(J Neurogastroenterol Motil 2021;27:87-96)

Previously, functional dyspepsia (FD) was divided into 3 categories of reflux-like, ulcer-like, and dysmotility-like FD. ${ }^{1} \mathrm{~A}$ paradigm shift has occurred in $\mathrm{FD}$, subdividing $\mathrm{FD}$ into epigastric pain syndrome and post-prandial discomfort. ${ }^{2}$ According to the American and Canadian guidelines of FD management, in Helicobactyer pylori-positive patients, $H$. pylori eradication therapy should be considered the first-line treatment. ${ }^{3}$ However, considering the high prevalence of $H$. pylori in Korea, $H$. pylori eradication therapy is recommended when proton pump inhibitors (PPIs) and prokinetics are not effective. ${ }^{4}$ Meta-analysis shows significant but modest efficacy of $H$. pylori eradication on long-term resolution of FD symptoms. ${ }^{5}$ H. pylori eradication therapy can be applied in cases where PPIs and prokinetics are not effective, or in young patients with chronic dyspeptic symptoms in Korea. In contrast, in patients with FD who do not respond to PPIs, $H$. pylori eradication therapy, or tricyclic antidepressant therapy, treatment with prokinetics should be tried according to the American and Canadian guidelines. Where does this difference come from? Postprandial fullness is the most troublesome symptom in FD patients, aggravated by a meal. ${ }^{6}$ Therefore, prokinetics, improving gastric emptying, relaxing the fundus, and increasing gastric accommodation, may have a role in the treatment of FD. ${ }^{7}$ However, most studies on prokinetics had significant and unexplained heterogeneity. Small studies showed positive results but larger trials could not demonstrate significant efficacy. $^{3}$

In the Journal of Neurogastroenterology and Motility, a randomized clinical trial of 119 patients with FD (by Rome III criteria) conducted by Park et $\mathrm{al}^{8}$ evaluated the efficacy and safety of once-a-day DWJ1252 (Gasmotin SR; Daewoong Pharm Co, LTD, Seoul, Korea), a sustained-release formulation of Gasmotin, compared with Gasmotin 3-times-a-day, in patients with FD. The primary endpoint was the change in gastrointestinal symptom (GIS) scores from baseline, assessed by GIS questionnaires on a 5-point Likert scale after 4 weeks of treatment. The study showed that the GIS scores at week 4 were significantly reduced $-10.04 \pm 4.45$ points in the Gasmotin SR group and $-10.86 \pm 5.53$ in the Gasmotin 3 -times-a-day group $(P<0.001)$. The GIS changes from baseline were not different between the 2 groups (difference, 0.82 points; $95 \% \mathrm{CI},-1.17$ to $2.81 ; P=0.643)$. The other outcomes of interest demonstrated that dyspepsia-specific quality of life scores significantly increased in the 2 groups after week 4 of treatment $(+63.82 \pm 82.91$ and $+67.12 \pm 81.11, P<0.001)$, with no difference between the test

Received: November 27, 2020 Revised: December 3, 2020 Accepted: December 8, 2020

(a) This is an Open Access article distributed under the terms of the Creative Commons Attribution Non-Commercial License (http://creativecommons. org/licenses/by-nc/4.0) which permits unrestricted non-commercial use, distribution, and reproduction in any medium, provided the original work is properly cited.

*Correspondence: Jae Hak Kim, MD

Department of Internal Medicine, Dongguk University College of Medicine, Dongguk University llsan Hospital, Dongguk-ro 27, Ilsandong-gu, Goyang, Gyeonggi-do 10326, Korea

Tel: +82-319617127, Fax: +82-319617141, E-mail: kimjaehak@dumc.or.kr 
and control groups $(P>0.99)$.

Gasmotin SR has a diffusion controlled-release system, which means the release rate is limited by the diffusion of the drug through a water-insoluble membrane. Frequent medication-taking leads to treatment non-adherence. The extended-release formulation of a drug can improve treatment adherence in patients with chronic diseases ${ }^{9}$ and drug compliance also matters in short-term disease treatment. ${ }^{10}$

Another controlled-release tablet, UI05MSP015CT (Gastiin CR; Korea United Pharm Inc, Seoul, Korea), is also available in Korea. A similar study was conducted with 138 patients with FD who received either UI05MSP015CT or mosapride 3-times-a-day as controls. ${ }^{11}$ It showed that changes in GIS scores at week 4 were $-9.69 \pm 6.44$ in the UI05MSP015CT group and $-10.01 \pm 5.92$ in the control group. The mean difference in GIS changes between the groups was $0.33(95 \% \mathrm{CI},-1.75$ to $2.41 ; P=0.755)$.

A study by Park et $\mathrm{al}^{8}$ regarding the efficacy of Gasmotin SR in FD lacked a placebo arm. In a randomized clinical trial of FD, the rate of response to the placebo was $30 \%$ to $60 \% .^{12,13}$ Since the negative results of a placebo-controlled, randomized study of mosapride were reported, ${ }^{12}$ mosapride was examined in FD and was not shown to be more effective than placebo in a meta-analysis of 13 randomized trials. ${ }^{7}$ For this reason, the clinical effectiveness of mosapride in patients with FD has been evaluated by the comparison to other drugs without a placebo group. ${ }^{14}$ Even though Gasmotin $\mathrm{SR}$ is a once-a-day tablet, better compliance with this drug could not be demonstrated due to the limitation of blinding. However, this study suggested that Gasmotin SR may achieve better compliance than conventional Gasmotin.

Acknowledgement: This study was supported by Dongguk University Research fund of 2020.

Financial support: None.

\section{Conflicts of interest: None.}

\section{References}

1. Talley NJ. Non-ulcer dyspepsia: myths and realities. Aliment Pharmacol Ther 1991;5(suppl 1):145-162.

2. Tack J, Talley NJ, Camilleri M, et al. Functional gastroduodenal disorders. Gastroenterology 2006;130:1466-1479.

3. Moayyedi P, Lacy BE, Andrews CN, Enns RA, Howden CW, Vakil N. ACG and CAG clinical guideline: management of dyspepsia. Am J Gastroenterol 2017;112:988-1013.

4. Oh JH, Kwon JG, Jung HK, et al. Clinical practice guidelines for functional dyspepsia in Korea. J Neurogastroenterol Motil 2020;26:29-50.

5. Delaney B, Ford AC, Forman D, Moayyedi P, Qume M. Initial management strategies for dyspepsia. Cochrane Database Syst Rev 2005:CD001961.

6. Bisschops R, Karamanolis G, Arts J, et al. Relationship between symptoms and ingestion of a meal in functional dyspepsia. Gut 2008;57:14951503.

7. Bang CS, Kim JH, Baik GH, et al. Mosapride treatment for functional dyspepsia: a meta-analysis. J Gastroenterol Hepatol 2015;30:28-42.

8. Park JH, Lee KN, Lee OY, et al. Efficacy and safety of DWJ1252 compared with gasmotin in the treatment of functional dyspepsia: a multicenter, randomized, double-blind, active-controlled study. J Neurogastroenterol Motil 2021;27:87-96.

9. Ingersoll KS, Cohen J. The impact of medication regimen factors on adherence to chronic treatment: a review of literature. J Behav Med 2008;31:213-224.

10. Malfertheiner P, Megraud F, O'Morain CA, et al. Management of Helicobacter pylori infection--the Maastricht IV/ Florence Consensus Report. Gut 2012;61:646-664.

11. Yoon H, Lee DH, Lee YH, et al. Efficacy and safety of UI05MSP015CT in functional dyspepsia: a randomized, controlled trial. Gut Liver 2018;12:516-522.

12. Hallerbäck BI, Bommelaer G, Bredberg E, et al. Dose finding study of mosapride in functional dyspepsia: a placebo-controlled, randomized study. Aliment Pharmacol Ther 2002;16:959-967.

13. Pittayanon R, Yuan Y, Bollegala NP, Khanna R, Leontiadis GI, Moayyedi P. Prokinetics for functional dyspepsia. Cochrane Database Syst Rev 2018;10:CD009431.

14. Hongo M, Harasawa S, Mine T, et al. Large-scale randomized clinical study on functional dyspepsia treatment with mosapride or teprenone: Japan Mosapride Mega-Study (JMMS). J Gastroenterol Hepatol 2012;27:62-68. 